Anatomy in Diagnostic Imaging by $\mathbf{P}$ Hckenstein and $\mathbf{J}$ Tranum - Jensen $2^{\text {nd }}$ edition, published by Blackwell publishing, paper back with 416 pages, Rs 2800/-

Tn depth knowledge of anatomy is central to interpretation of multiplanar cross-sectional imaging. Moreover, it is important to correlate 2 dimensional radiographic image with a relevant crosssectional image. This book achieves the same through dealing with body part anatomy in the regional manner. The first fifty odd pages are devoted to outline the principles and technique of all imaging

Kuby Immunology, $4^{\text {th }}$ Edition year 2000. Authors : Richard A Goldsby (Amherst College), Thomas J Kindt (NIH, Bethesda), Barbara A Osborne (University of Massachusetts at Amherst). Publishers : WH Freeman and Company. ISBN : 0-7167-33315. Website: http://www.whfreeman.com/immunology. Pages 650. Illustrations:482. Printed in the USA. Glossy pages and excellently bound in hardcover.

$\mathrm{T}$

his is a clearly written clinical presentation of immunology at molecular and cellular levels explaining how the body reacts to disease. The book offers a cutting edge coverage of new discoveries and concepts in this rapidly evolving field. Unlike other books on the subject, every chapter offers clinical application of the knowledge of immunology or procedures discussed in the text in a separate box. Profusely illustrated, the book seeks to make even the most difficult areas of immunology crystal clear to the reader in the form of easily comprehensible graphics.

Campbell's Operative Orthopaedics by S. Terry Canale, MD, Tenth Edition : 2003.ISBN 0-808-90014-5. Published by Mosby Inc., 11830 Westline Industrial Drive, St Louis. 4283 pages with over 9000 illustrations in four Volumes. Price $\$ 400$.

I

$t$ is a matter of pride for all Orthopaedic surgeons that significant ladvances are taking place in the field of arthroscopy and arthroscopic surgery, arthroplasty and in the subspecialties of sports medicine, hand, foot, paediatrics, joint reconstruction and rehabilitation. The inventions and innovations in each of these areas have lessened the burden of disease on our patients. Campbell's Operative Orthopaedics remains the bible for the orthopaedic surgeons the world over. All the new operative advances have been included in the latest edition. The established orthopaedic procedures have been retained as in the previous edition. The book is clear and concise and all aspects of orthopaedic surgery have been covered in details.

Volume one includes general principles in orthopaedics, arthrodesis and arthroplasty, amputations, infections, tumours and non-traumatic soft tissue disorders. Volume two includes congenital processes. Subsequently, each body region is sequentially illustrated on all relevant imaging modalities.

This book is recommended to be introduced as a must for all the PG residents within the first year of their residency. A real value for money acquisition for the department.

\section{Contributed by:}

\section{Lt Col SS Naware}

Classified Specialist (Radiodiagnosis and Imaging), Military Hospital,Namkum.
At the end of each chapter there are latest references and websites that offer more details as also a set of self-test questions that are practical and designed on fundamental issues discussed in the chapter. There are excellent sections on flowcytometry, immunofluorescence, immunoelectron microscopy, microarray technology, chemiluminescence, ELISA, recombinant DNA technology, transplantation immunology, autoimmunity and apoptosis. The authors discuss the immunology of HIV and AIDS in detail and explain the applications of various tests in this field. What is strikingly different in this book is the strong clinical focus. Application of a particular idea or a procedure is given importance. The book is a must for any medical library and will be a boon for the postgraduates and practising clinicians alike.

\section{Contributed by :}

\section{Lt Col (Mrs) Ketoki Kapila}

Associate Professor, Department of Microbiology, Armed Forces Medical College, Pune - 411040. anomalies, osteochondrosis, nervous system disorders and fractures and dislocations in children and spine. Volume three includes sports medicine, arthroscopy, fractures and dislocations in adults. Finally, volume four includes peripheral nerve injuries, microsurgery, hand and foot and ankle.

Mainstream, proven techniques, alongwith some promising cutting edge techniques and even some of the older techniques that are applicable to the developing countries of the world especially, where the latest technologies are not available, have been included in this edition. Further this edition includes a CD-ROM with videos that demonstrate commonly performed orthopaedic procedures. Also, contents of the four volume set is available both in print and CD-ROM. For quick references, the techniques are numbered in each chapter and all the techniques in each volume are listed on the front and back end sheets. This helps in quick referrals.

\section{Contributed by:}

Col AK Sharma

Professor and Head, Department of Orthopaedics, Armed Forces Medical College, Pune - 411040. 